\title{
BIAYA GAJI, BIAYA PELATIHAN TENAGA KERJA, JUMLAH KARYAWAN DAN PRODUKTIVITAS KARYAWAN (STUDI KASUS PADA PERUSAHAAN PERKEBUNAN DI BEI TAHUN 2013-2018)
}

\author{
Meita Pragiwani ${ }^{1}$, Muhammad Ammar ${ }^{2}$, Mohammad Benny Alexandri ${ }^{3}$ \\ ${ }^{1}$ Sekolah Tinggi Ilmu Ekonomi Indonesia, ${ }^{2}$ Universitas Padjadjaran \\ meitasoetopo@gmail.com¹, ammar94stei@gmail.com², mohammad.benny@unpad.ac.id³
}

\begin{abstract}
ABSTRAK
Tujuan penelitian ini mengidentifikasi variabel jumlah karyawan, biaya gaji dan biaya pelatihan kerja signifikan mempengaruhi produktivitas karyawan pada perusahaan sektor perkebunan yang ada di BEI . Pengujian data menggunakan analisis regresi data panel. Metode penentuan model data yang tepat menggunakan metode uji Hausman tes. Analisis membuktikan variabel jumlah karyawan, biaya gaji dan biaya pelatihan tenaga kerja berpengaruh secara parsial terhadap produktivitas karyawan. Dengan tingkat keyakinan 95\% didapat baahwa jumlah karyawan, biaya gaji dan biaya pelatihan tenaga kerja dapat menginterpretasikan produktivitas karyawan sebesar 66,6\% sedangkan sisanya 33,4\% diluar penelitian.
\end{abstract}

Kata Kunci : Produktivitas Karyawan, Jumlah Karyawan, Biaya Gaji, Biaya Pelatihan Tenaga Kerja.

\begin{abstract}
The purpose of this study is to identify the variable number of employees, salary costs and job training costs significantly affect employee productivity in plantation sector companies on the IDX. Testing data using panel data regression analysis. The method of determining the right data model uses the Hausman test method. The analysis proves the variable number of employees, salary costs and labor training costs partially affect employee productivity. With a 95\% confidence level obtained that the number of employees, salary costs and labor training costs can interpret employee productivity by $66.6 \%$ while the remaining $33.4 \%$ are outside research.
\end{abstract}

Keywords: Employee Productivity, Number of Employees, Salary Costs, Labor Training Costs.

\section{PENDAHULUAN}

Kemajuan peradaban teknologi yang semakin canggih dan persaingan bisnis yang semakin ketat kini sedang dialami di negara maju maupun di negara berkembang khususnya di Negara Indonesia. Dalam kondisi ini, setiap perusahaan-perusahaan dituntut untuk segera mungkin mengubah pola bisnisnya dari yang bernama labor-based business (bisnis berbasis tenaga kerja) menjadi kearah knowledge based business (bisnis berbasis pengetahuan).

Produktivitas karyawan yang terus meningkat tentunya secara pasti akan meningkatkan kekayaan (assets) perusahaan.
Semua pendiri dan pemilik perusahaan mempunyai visi jangka panjang agar perusahaannya terus maju dan berkembang dengan selalu membukukan laba yang meningkat dan sustainable (berkelanjutan) atas setiap investasi yang ditanamkan di perusahaan,

Para pelaku bisnis perkebunan, terutama dalam industri kelapa sawit dalam menghadapi tahun bisnisnya penuh dengan kehatian-hatian dan analisis yang sangat matang. Hal ini disebabkan beberapa tahun belakang terjadi resesi penurunan pertumbuhan 
ekonomi global terutama di Eropa dan Amerika yang berdampak pada Indonesia.

Rahardjo (2009) menyatakan, sesuai dengan karakteristik internal perkebunan, kunci utama bisnis perkebunan adalah jumlah biaya yang dikeluarkan dan jumlah unit produksi yang dihasilkan atau bisa diartikan sebagai tingkat maksimum dari produktivitas atau output yang di hasilkan oleh perusahaan. Kinerja perusahaan yang optimum dalam menghasilkan produksi dan mampu mengendalikan serta menekan biaya produksi seperti biaya gaji dari para tenaga kerja serta memaksimumkan sumber daya manusia yang dimilikinya akan sangat menentukan profitabilitas dan meningkatkan produktivitas perusahaan

Untuk mengetahui kondisi dan keadaan dari suatu perusahan, para investor maupun kreditur harus melakukan analisis terhadap produktivitas dan kemampuan perusahaan dalam mengimplementasikan sumber daya yang dimiliki perusahaan. Salah satu tujuan dari analisis adalah untuk menaksir nilai dan kinerja perusahaan di masa mendatang

Dalam memotivasi karyawan agar dapat meningkatkan kinerja tentu di support atau di dukung dengan pemberian kompensasi yaitu berupa gaji atau upah yang sepadan atas timbal balik hasil pencapaian yang dilakukan oleh para karyawan, ini terbukti dengan terdapatnya tren kenaikan biaya gaji yang dikeluarkan perusahaan selain dari faktor inflasi dan juga peraturan pemerintah. Dari besarnya kenaikan gaji ini tentu para manajer berharap dapat meningkatkan kinerja karyawan yang nantinya akan berpengaruh kepada produktivitas kerja perusahaan

Selain gaji untuk meningkatkan produktivitas perusahaan, para manajer tentu sadar bahwa faktor utama dari pencapaian tingkat produktivitas yang tinggi tidak lepas dari peranan perusahaan dalam melakukan hal pembinaan serta pelatihan kepada para karyawan yang dimilikinya. Biaya pelatihan serta pengembangan tenaga kerja tentu bukanlah biaya yang nilainya sedikit dikeluarkan oleh perusahaan, dalam perjalanan nya tentu perusahaan tidak terkecuali perusahaan yang bergerak di bidang usaha perkebunan berharap dengan diadakannya serta dikeluarkan biaya pelatihan dan pengembangan tenaga kerja mampu mendorong tingkat produktivitas kerja karyawan yang tinggi.

\section{TINJAUAN PUSTAKA}

\section{Manajemen Sumber Daya Manusia}

Menurut Handoko (2012), manajemen sumber daya manusia adalah penarikan, seleksi, pengembangan, pemeliharaan, dan penggunaan sumber daya manusia untuk mencapai baik tujuan-tujuan individu maupun organisasi.

Menurut Desseler (2015), manajemen sumber daya manusia adalah proses untuk memperoleh, melatih, menilai, dan mengompensasi karyawan dan untuk mengurus relasi tenaga kerja, kesehatan dan keselamatan, serta hal-hal yang berhubungan dengan keadilan.

\section{Biaya Gaji}

Menurut Dewan Penelitian Pengupahan Nasional memberikan definisi bahwa upah adalah suatu penerimaan sebagai suatu imbalan dari pemberian kerja kepada penerima kerja atau suatu pekerjaan/jasa yang telahdan akan dilakukan berfungsi sebagai jaminan kelangsungan hidup yang layak, kemanusiaan dan produksi dinyatakan atau dinilai dalam bentuk uang yang ditetapkan menurut suatu persetujuan, UU dan peraturan dan dibayarkan atas dasar perjanjian kerja antara pemberian kerja dan penerimaan kerja.

\section{Faktor-Faktor yang Mempengaruhi Tinggi Rendahnya Tingkat Upah}

Menurut Panjojo dan Suad (2006) terdapat beberapa faktor yang mempengaruhi tingkat tinggi rendahnya upah antara lain :

\section{a. Penawaran dan Permintaan Tenaga Kerja}

b. Organisasi buruh 
c. Kemampuan untuk Membayar

\section{Biaya Pelatihan Tenaga Kerja}

Menurut Widodo (2015), pelatihan merupakan serangkaian aktivitas individu dalam meningkatkan keahlian dan pengetahuan secara sistematis sehingga mampu memiliki kinerja yang profesional di bidangnya

Menurut Rivai dan Sagala (2013), pelatihan adalah proses secara sistematis mengubah tingkah laku pegawai untuk mencapai tujuan organisasi. Pelatihan berkaitan dengan keahlian dan kemampuan pegawai untuk melaksanakan pekerjaan saat ini.

\section{Tujuan Pelatihan}

Menurut

Widodo

(2015), mengemukakan bahwa tujuan pelatihan yang dilakukan oleh perusahaan adalah untuk meningkatkan produktivitas, meningkatkan kualitas, mendukung perencanaan SDM, meningkatkan moral anggota, memberikan kompensasi yang tidak langsung, meningkatkan kesehatan dan keselamatan kerja, mencegah kedaluarsa kemampuan dan pengetahuan personel, meningkatkan perkembangan kemampuan dan keahlian personel.

\section{Produktivitas Karyawan}

Menurut Simanjuntak

"Produktivitas merupakan perbandingan hasil yang dicapai (keluaran) dengan keseluruhan sumber daya (masukan) yang digunakan per satuan waktu.” Mulyadi (2016) mengartikan produktivitas pekerja pada suatu kemampuan maksimal seseorang pekerja untuk menghasilkan output.

\section{Faktor Yang Mempengaruhi Produktivitas}

Produktivitas di pengaruhi oleh lima faktor (Gomes : 2010):
1. Knowledge
2. Skill
3. Abilities
4. Attitude
5. Behavior.

\section{Paradigma Penelitian}

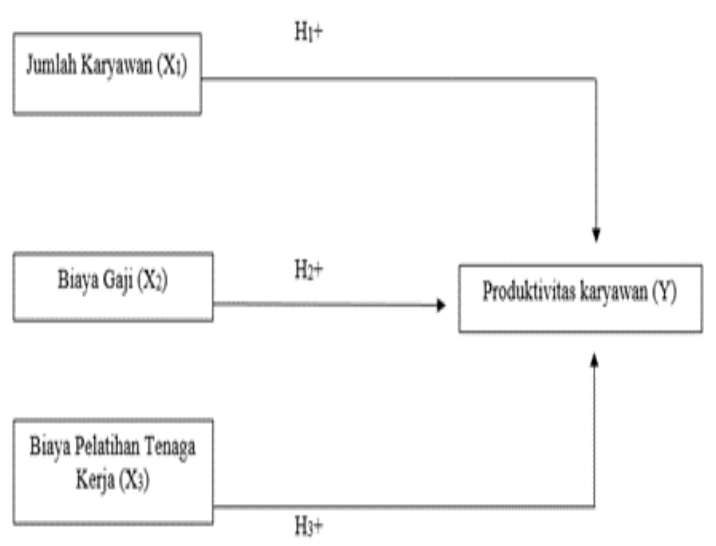

\section{Hipotesis}

$\mathrm{H}_{1}$ : Terdapat pengaruh positif jumlah karyawan terhadap produktivitas karyawan perusahaan perkebunan yang terdaftar di BEI periode tahun 2013-2018.

$\mathrm{H}_{2}$ : Terdapat pengaruh positif biaya gaji terhadap produktivitas karyawan perusahaan perkebunan yang terdaftar di BEI periode tahun 2013-2018.

$\mathrm{H}_{3}$ : Terdapat pengaruh positif biaya pelatihan tenaga kerja terhadap produktivitas karyawan perusahaan sawit yang terdaftar di BEI tahun 2013-2018.

\section{METODE PENELITIAN}

Penelitian ini dilakukan dengan mengambil data sekunder laporan tahunan perusahaan perkebunan yang terdaftar di BEI melalui situs web IDX atau web resmi masing masing perusahaan.

Dalam penelitian ini digunakan teknik Purposive Sampling karena berdasarkan pertimbangan tertentu. Pertimbangan atau kriteria yang digunakan dalam penelitian ini adalah perusahaan telah IPO atau Initial Public Offering mulai tahun 2012 , telah mengumumkan report laporan tahunan semenjak tahun 2013 atau 6 tahun terakhir sampai dengan tahun 2018 dan dalam pencatatan laporan keuangannya merinci tentang total jumlah karyawan, biaya gaji dan biaya pelatihan tenaga kerja sehingga didapat 8 sampel perusahaan yang akan dijadikan penelitian. 
Pengolahan data dalam analisis ini menggunakan program software Eviews (Econometric Views) versi 10 untuk analisis data. Penelitian ini menggunakan analisis linear berganda, sebelum melakukan pengujian regresi terlebih dulu dilakukan uji asumsi klasik untuk mengetahui apakah data yang digunakan telah memenuhi syarat dan kententuan dalam model regresi dan melakukan pengujian model data panel yang paling tepat dalam penelitian ini.

Dalam penelitian ini, untuk mengestimasi data panel menggunakan uji hausman. Uji Hausman digunakan untuk memilih model terbaik antara Fixed Effect Model (FEM) atau Random Effect Model (REM).

1. Analisis Regresi Linear Berganda

$\hat{\mathrm{Y}}=\mathrm{b} 0+\mathrm{b} 1 \mathrm{x} 1+\mathrm{b} 2 \mathrm{x} 2+\mathrm{b} 3 \mathrm{x} 3+\dot{\varepsilon} \quad$ (Rumus Persamaan Regresi 3.1)

Keterangan :

$\hat{\mathrm{Y}}$

$=$ Produktivitas Karyawan

$\mathrm{X} 1=$ Jumlah Karyawan

$\mathrm{X} 2$

$=$ Biaya Gaji

X3

$=$ Biaya Pelatiahan Tenaga

Kejra

$b \quad=$ Intercept

\section{Koefisien Determinasi (R2)}

Dalam penelitian ini, peneliti menggunakan R2 dengan tujuan untuk mengukur besarnya pengaruh variabel bebas (X) terhadap variabel terikat $(\mathrm{Y})$. Koefisien determinasi pada dasarnya untuk mengukur seberapa jauh kemampuan model dalam menerangkan variasi variabel dependen

\section{HASIL DAN PEMBAHASAN Isi Hasil dan Pembahasan}

Hasil dari data yang telah didapat dan diolah selama proses penelitian dijelaskan sebagai berikut;
1) Penentuan estimasi model data panel yang terbaik dalam penelitian ini adalah menggunakan model Random Effect Model (REM)

2) Data yang diperoleh dilakukan uji asumsi klasik sebagai syarat uji kelayakan data

3) Pengolahan data menggunakan software Econometric Views

Model penelitian ini adalah sebagai berikut :

$\mathrm{Y}=-32,39768+(-0,004701) \mathrm{x} 1+18,00621 \mathrm{x} 2$

$+6,98 \times 3+e$

Atau

Produktivitas $=-32,39768+(-0,004701)$ Jumlah Karyawan + 18,00621 Biaya Gaji + 6,98 Biaya Pelatihan Tenaga Kerja + e

\section{Koefisien Determinasi}

Dari hasil pengolahan didapat nilai koefisien determinasi 0,665928 dilihat dari nilai Adjusted R-squared, yang artinya model dari variabel independent dalam hal ini Jumlah Karyawan, Biaya Gaji dan Biaya Pelatihan Tenaga Kerja mampu menjelaskan Produktivitas Karyawan sebesar 0,665928 atau $66,6 \%$, sedangkan sisanya yaitu sebesar 33,4\% merupakan faktor-faktor lain dari variabel luar penelitan ini.

\section{Uji t (parsial)}

TTabel 4.13 Hasil Uji t (Parsial)

\begin{tabular}{ccccc}
\hline Variable & Coefficient & Std Error & 1.Statistic & Prob. \\
\hline C & 32.39768 & 78.57943 & 0.412292 & 0.6821 \\
X1_JUMLAH_KARYAWAN & 0.004701 & 0.001762 & 2668285 & 0.0106 \\
X2_BIAYA_RATA_RATA_GAJI & 18.00621 & 2.026798 & 8.884066 & 0.0000 \\
X3_B_AAY_PELATIHAN & $6.98 E-05$ & $2.62 E-05$ & 2.666954 & 0.0107 \\
\hline
\end{tabular}

Adapun penjelasan terhadap masing-masing variabel adalah sebagai berikut : 
a. Jumlah karyawan nilai sig 0,0106 atau $<$ 0,05 sehingga jumlah karyawan berpengaruh terhadapa produktivitas.

b. Biaya Rata-rata Gaji nilai sig 0,0000 atau $<0,05$ sehingga biaya gaji berpengaruh terhadap produktivitas

c. Biaya Pelatihan Tenaga Kerja nilai sig 0,0107 atau < 0,05 sehingga biaya pelatihan tenaga kerja berpengaruh terhadap produktivitas

Hasil penelitian menunjukan bahwa terdapat pengaruh yang signifikan Jumlah karyawan, Biaya gaji dan biaya pelatihan tenaga kerja terhadap produktivitas karyawan. Hal ini berarti bahwa semakin komposisi jumlah tenaga kerja, gaji yang diberikan dan pelatihan yang dilakukan semakin meningkatkan tingkat produktivitas kerja karyawan perusahaan sektor perkebunan di Bursa Efek Indonesia.

\section{SIMPULAN}

1. Jumlah Karyawan secara parsial berpengaruh terhadap Produktivitas Karyawan. Hal ini dibuktikan dengan nilai signifikan maka H0 ditolak Ha diterima, artinya perusahaan-perusahaan sector perkebunan yang di BEI telah dapat menetapkan komposisi penempatan para Sumber Daya Manusia atau pekerja secara efektif ,akan tetapi perlu diperhatikan bahwa jika perusahaan melakukan perekrutan karyawan yang berlebihan akan memberikan dampak pada penurunan tingkat produktivitas oleh karena itu divisi HRD dituntut untuk terus menyeimbangkan antara jumlah pekerja dengan kebutuhan perusahaan agar tetap optimal

2. Biaya Gaji secara parsial mempunyai pengaruh terhadap produktivitas karyawan. Maka dapat disimpulkan H0 ditolak Ha diterima, artinya dalam hal pemberian komposisi kompensasi berupa gaji yang dikeluarkan perusahaan kepada para karyawannya telah tepat, ini tercermin dari keseluruhan biaya gaji dapat mendongkrak tingkat produktivitas karyawan.
3. Biaya Pelatihan Tenaga Kerja secara parsial berpengaruh terhadap produktivitas karyawan. Maka dapat disimpulkan H0 ditolak dan Ha diterima, artinya program pelatihan tenaga kerja yang diterapkan perusahaan-perusahaan sector perkebunan untuk menunjang produktivitas karyawan mampu mendorong semangat kerja bagi setiap karyawan dan ini berdampak pada produktivitas yang tercapai secara maksimal, oleh karena itu pihak HRD dapat melakukan evaluasi kembali dan mempertahankan program-program pelatihan dan memilih mana program pelatihan yang paling tepat untuk meningkatkan produktivitas karyawan.

\section{DAFTAR PUSTAKA}

Akhyar Yusuf Lubis. 2014. Teori dan Metodologi Ilmu Pengetahuan Sosial. Budaya Kontemporer. Jakarta : Rajawali Press.

Ambar. 2009. Manajemen Sumber Daya Manusia. Yogyakarta: Graha Ilmu

Ansofino. 2016. Buku Ajar Ekonometrka. Yogyakarta : Deepublish

Bougie dan Sekaran. 2013. Edisi 5 Research Methods for Business: A skill

Building Approach. New York: John Wiley.

Dini, Muammar. 2016. Pengaruh Pelatihan Terhadap Produktivitas Kerja Karyawan. E-Journal Administrasi Bisnis Volume 4 nomor 1

Dessler, Gary. 2015. Manajemen Sumber Daya Manusia. Jakarta: Salemba Empat.

Eko, Widodo Suparno. 2015. Manajemen Pengembangan Sumber Daya Manusia. Yogyakarta : PUSTAKA PELAJAR.

Gaol. 2014. A to Z Human Capital (Manajemen Sumber Daya Manusia) Konsep, Teori, dan Pengembangan Dalam Konteks Organisasi Publik dan Bisnis, Jakarta : PT. Gramedia Widiasarana.

Gie, The Liang. 2009. Administrasi Perkantoran Modern. Yogyakarta : Liberty

Gomes. 2010. Manajemen Sumber Daya Manusia. Yogyakarta: Andi

Handoko, T. Hani. 2012. Manajemen Personalia Dan Sumber Daya Manusia. Yogyakarta : BPFE

Hanief, Yulingga Nanda dan Wasis 


\begin{abstract}
Himawanto. Statistik Pendidikan. Yogyakarta: CV Budi Utama.

Hasibuan, Malayu. 2016. Manajemen Sumber Daya Manusia.Jakarta: PT Bumi Aksara

Hartono, Jogiyanto. 2011.Metodologi Penelitian Bisnis: Salah Kaprah dan Pengalaman-pengalaman. Yogyakarta : BPFE.
\end{abstract}

Komarudin. 2012. Manajemen Sumber Daya Manusia. Jakarta: STIA-LAN Press.

Konings, Jozef. 2010. Pengaruh Pelatihan Tenaga Kerja Dan Gaji Terhadap Produktivitas. Discussion Paper IZA No. 4731

Kusriyanto, Bambang.2005. Meningkatkan Produktivitas Karyawan. Jakarta : PT.Gramedia Pustaka Utama

Mangkunegara. 2013. Manajemen Sumber Daya Manusia. Bandung : Remaja Rosdakarya

Mathis, R.L. \& J.H. Jackson. 2013. Human Resource Management: Manajemen Sumber Daya Manusia. Terjemahan Dian Angelia. Jakarta: Salemba Empat.

Meager, Nigel. 2011. Upah Produktivitas Dan pekerjaan : Tinjauan Teori Dan Data Internasional. European Employment Observatory Thematic Expert ad-hoc Paper

Mulyadi.2016. Sistem Informasi Akuntansi. Jakarta: Salemba Empat.

Nadia, Nasir. 2008. Analisa Pengaruh Tingkat Upah, Masa Kerja, Usia Terhadap Produktivitas Tenaga Kerja. Jurnal Ekonomi Pembangunan Universitas Brawijaya Malang Ngurah, Gede. 2016 Pengaruh Modal Dan Tenaga Kerja Terhadap Produksi Dan Pendapatan . EJurnal EP Unud, 8 [2]: 453-485

Notoatmodjo, S. 2010. Metodologi Penelitian Kesehatan. Jakarta : Rineka Cipta.

Nuryanto dan Zulfikar Bagus Pambuko. 2018 Eviews untuk Analisis Ekonometrika Dasar: Aplikasi dan Interpretasi. Magelang: UNIMMA PRESS

Pandojo dan Suad. 2006. Manajemen Personalia Edisi Keempat Yogyakarta : BPFE UGM

Panjaitan, R. 2011. Manajemen Keperawatan: Manajemen Keperawatan di Ruang Rawat. Jakarta: Sagung Seto.

Poerwono 2013, Tata Personalia Edisi ke-III, Jakarta : Djambatan
Rahardjo. 2009. Pengaruh Gaya Kepemimpinan Terhadap Kinerja Karyawan Sektor Perkebunan Surabaya. Jurnal Jurnal Akuntansi Bisnis Vol.1 No.1

Ria Chainar Elli. 2017. Pengaruh Pendidikan dan Latihan Tenaga Kerja Terhadap Peningkatan Produktifitas Kerja Karyawan. Jurnal Ekonomika dan Manajemen Vol. 6 No. 1

Rismayadi, Budi. 2015. Faktor-faktor Yang Mempengaruhi Produktivitas Karyawan. Jurnal Manajemen \& Bisnis Vol, 1 No, 1

Rivai dan Sagala. 2013. Manajemen Sumber Daya Manusia untuk Perusahaan. Jakarta : Rajawali Pers

Rony, Salinding, 2011 . Analisis Pengaruh Pelatihan Terhadap Produktivitas Kerja Karyawan Pada PT. Erajaya Swasembada Cabang. Jurnal Ekonomika dan Manajemen Vol. 2No. 1

Rusminingsih Diah. 2010. Pengaruh Pengembangan Sumber Daya Manusia Terhadap Produktivitas Kerja Karyawan. Jurnal Ekonomi Modernisasi Fakultas Ekonomi-Universitas Kanjuruhan Malang Vol 6,No 1

Santoso. 2018. Statistik Parametik. Jakarta : PT Gramedia Pustaka Umum.

Saprudin.2018. Pengaruh Pelatihan Dan Kompensasi Terhadap Produktivitas Kerja Karyawan. Journal on information system applied, management, accounting and research vol 2 no 2

Singh.2000. A Trestie on Phytochemistry. Emedia Sience Ltd.

Simanjuntak, Payaman. 2012. Produktivitas Kerja Pengertian dan Ruang Lingkupnya, Prisma : Jakarta.

Sumarsono, S. 2009.Ekonomi Sumber Daya Manusia Teori dan Kebijakan Publik. Yogyakarta : Graha Ilmu.

Sinungan.2014. Produktivitas Apa dan Bagaimana. Jakarta : Bumi Aksara

Sufren, dan Natanael, Yonathan. 2013. Mahir Menggunakan SPSS Secara Otodidak. Jakarta: Kompas Gramedia.

Sugiyono. 2017. Metode Penelitian Kuantitatif Kualitatif dan R\&D. Bandung:Alfabeta.

Sutrisno, Edi. 2015. Manajemen Sumber Daya Manusia Edisi pertama. Jakarta: 
Kencana Prenada Media Group

Susilo Agus. 2003. Pengaruh Gaji, Kondisi kerja Dan Program Pelayanan Bagi Karyawan Terhadap Produktivitas Kerja. Jurnal Ekonomi dam Bismis Universitas Sebelas Maret Surakarta

Syaiful, Anwar. 2014. Pengaruh Pelatihan Kerja, Pengalaman Kerja dan Kompensasi Terhadap Produktivitas Kerja Karyawan. Jurnal Ekonomi dan Bisnis Universitas Dian Nuswantoro Semarang

Umar, Husein. 2004. Riset Sumber Daya Manusia Dalam Organisasi. Jakarta : Gramedia Pustaka Utama.

Ug Kang Dong. 2016. Efek Manfaat Jumlah Karyawan Terhadap Produktivitas Karyawan.. The Journal of Applied Business Research-September/October 2016 Volume 32, Number 5 Korea Selatan

Widodo, Agung. 2016. Pengaruh Pelatihan Dan Kompensasi Terhadap Produktivitas Karyawan. Journal Ekonomi Manajemen Universitas Nusantara PGRI Kediri

Widya Ayu Lestari. 2015. Pengaruh Pelatihan Tenaga Kerja Terhadap Produktivitas Karyawan. Jurnal Manajemen Universitas medan area 